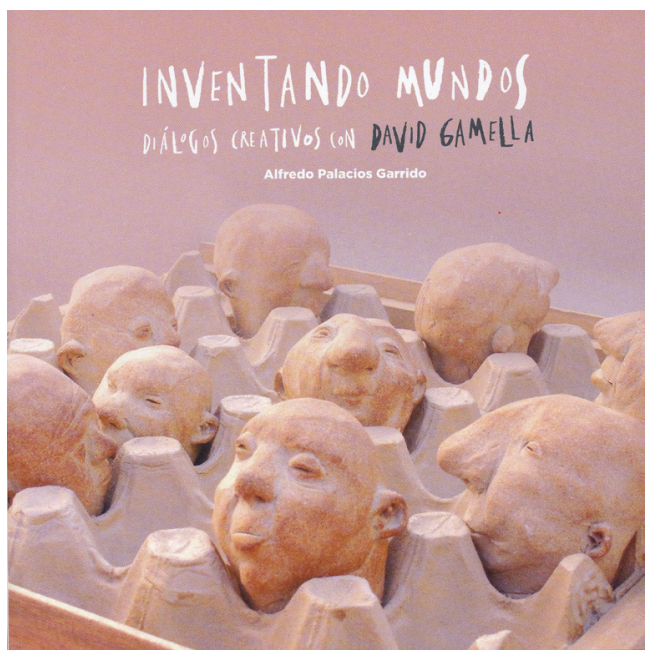

Inventando mundos. Diálogos creativos con David Gamella

Alfredo Palacios

Año: 2015 Lugar: Alcalá de Henares

Editorial: Centro Universitario Cardenal Cisneros

Colección Diálogos Creativos. Páginas: 56

ISBN: 978-84-608-1313-2

\title{
Estableciendo redes entre artistas, alumnado de colegios y estudiantes de magisterio.
}

Se hace necesaria una mayor colaboración entre colectivos de docentes y artistas. Si este concierto imprescindible lo iniciamos en el momento en que se están formando los futuros docentes durante su etapa universitaria, entonces habremos avanzado mucho. Si además implicamos a centros educativos en la contienda, en ese caso tenemos ganada la batalla del acercamiento del público más joven hacia el arte contemporáneo. Así lo han venido defendiendo en los últimos años especialistas e investigadores, y así lo expresaba también María Dolores Soto González en su tesis titulada Espacios de inclusión e implicaciones educativas entre escuela, museo y universidad. Análisis desde la investigación-acción (Universitat de València, 2015). Desarrollar estas sinergias es lo que se pretende con la experiencia llevada a cabo entre el artista David Gamella (Madrid, 1971) y los estudiantes de Magisterio y Educación Social del Centro Universitario Cardenal Cisneros. El artífice de estas propuestas integradoras es el profesor Alfredo Palacios.

La idea de diálogo tiene espíritu humanista, y procede de una larga tradición filosófica. Quienes dialogan aquí son artistas y educadores. Al diálogo fructífero entre creatividad artística y pedagógica se une la participación entusiasta del alumnado escolar, que es en última instancia a quienes va dirigida esta experiencia innovadora. Este viaje dialogante se inicia con un capítulo que nos llama la atención: "El aula expandida". Aquí se no explica cuál ha sido la evolución de la Sala de Exposiciones del Centro de Recursos para el Aprendizaje y la Investigación del Centro Universitario Cardenal Cisneros (CUCC). El espacio expositivo se convierte en la clave del conjunto de acciones que posteriormente se llevarán a cabo en otros entornos educativos. En dicho espacio se establece el diálogo primigenio entre el artista (en este caso David Gamella) con los estudiantes universitarios, y seguidamente con los niños y las niñas de las escuelas que participan en el proyecto. Se trata por tanto de un espacio híbrido en el que se entrecruzan la cultura escolar, la universidad y el mundo del arte, un espacio detonante en el que se establecen 
diálogos entre niños, estudiantes universitarios y profesionales de las artes. Un lugar para generar preguntas e interrogantes que posteriormente tendrán su eco en las aulas universitarias y en los colegios. Asegura Palacios que los espacios educativos influyen en el aprendizaje. Y es cierto. De hecho, en ocasiones lo condicionan totalmente, teniendo en cuenta que muchas veces las aulas y los centros escolares siguen reflejando una concepción decimonónica de la educación. Es por ello que debemos empezar a fomentar espacios flexibles y polivalentes, lugares acogedores capaces de albergar diversidad de procesos e intercambios multidireccionales. Esta es la línea que siguen numerosos estudios actuales, como es el caso del volumen Entornos informales para educar en artes (PUV, 2017). Y así es como lo concibe Alfredo Palacios, motivando a su alumnado e implicándole en actividades que se llevan a cabo en espacios expositivos como museos y galerías de arte. En este caso, además, se cuenta con la participación directa del artista, lo cual genera un reto mucho más ingenioso. Es en ese momento cuando se inicia el verdadero diálogo.

Los estudiantes de Magisterio y Educación Social del CUCC han tenido de este modo la oportunidad de ejercer como mediadores entre las obras de arte de la exposición y los visitantes escolares que allí han acudido. Todo ello con la intención de incrementar las posibilidades educativas del arte, pero también como experiencia inicial en el desarrollo de diseños de talleres didácticos. El diálogo se convierte así en red de experiencias compartidas, tal y como comprobamos en el capítulo titulado "Tres itinerarios que se cruzan y tejen una trama de saberes". En dicho apartado se nos detalla el modelo a implementar. Trabajar mediante un proyecto es una forma efectiva de combinar el saber disciplinar y el saber didáctico, una tarea de difícil equilibrio para conseguir integrar el conocimiento propio de la materia con la didáctica. Debemos indicar que, además, la asignatura en la que se ha venido elaborando la propuesta es una materia que se imparte en inglés, dentro del enfoque CLIL (Content and Language Integrated Learning), con lo cual, a los lenguajes de las artes y de la pedagogía cabe añadir el aprendizaje de idiomas. El eje integrador del conjunto corre a cargo de las esculturas del artista David Gamella, una serie de personajes de quienes conocemos especialmente sus cabezas, trabajadas en arcilla, lo cual contrasta con el resto de materiales que son habituales en la obra de este artista, quien usa en la confección de los cuerpos telas, metales, y todo tipo de objetos encontrados. Gamella expone sus obras en la sala, y allí acuden los escolares, quienes conversan con los mediadores y con el artista. Así pues, el diálogo a tres bandas se multiplica y revierte en conocimiento mutuo. La siguiente fase de la experiencia consiste en llevar las esculturas a los colegios para continuar con nuevas actividades que implican a los docentes y a su alumnado, quienes relatan abiertamente sus intereses personales a partir de las piezas artísticas.

Numerosas fotografías ilustran cada uno de los aspectos que convergen en esta experiencia dialogante. Esculturas, alumnado, profesorado, artistas, entornos, relatos, encuentros. Un constante devenir de actividades participativas que delatan buenas prácticas, muy en la línea del trabajo que ya conocíamos de Alfredo Palacios, a quien seguimos con interés, ya que cada nueva apuesta acaba constituyendo un 
ejercicio honesto de innovación. Una vez más, este profesor universitario ha sabido impulsar y coordinar un espacio creativo de aprendizaje con el que se inicia la andadura de estos Diálogos Creativos que inventan mundos e infunden esperanzas. Entre los resultados de la investigación posterior, leemos la opinión de Carmen, quien asegura que "Como futuras maestras hemos de tener en cuenta que la educación artística debería ser considerada como una asignatura esencial, y debemos dar a los alumnos la posibilidad de expresarse usando el arte de todas las formas posibles". Esperamos poder disfrutar en el futuro de muchos más Diálogos Creativos.

Ricard Huerta. Universitat de València 